Max-Planck-Institut für demografische Forschung

Max Planck Institute for Demographic Research

Konrad-Zuse-Strasse 1 - D-18057 Rostock · GERMANY

Tel +49 (0) 3812081 - 0; Fax +49 (0) 3812081 - 202;

http://www.demogr.mpg.de

MPIDR WORKING PAPER WP 2007-033

NOVEMBER 2007

\title{
Fertility and Family Configurations in Sardinia
}

Laura Bernardi (bernardi@demogr.mpg.de)

Anna Oppo

(C) Copyright is held by the authors.

Working papers of the Max Planck Institute for Demographic Research receive only limited review. Views or opinions expressed in working papers are attributable to the authors and do not necessarily reflect those of the Institute. 


\section{Fertility and Family Configurations in Sardinia ${ }^{1}$}

\section{Laura Bernardi and Anna Oppo}

\section{Introduction}

Neither existing economic demographic theories nor theories that emphasize a move from familism to individualism have proven to be adequate to the task of explaining Italy's very low fertility (Kertzer et al. 2006). As a result, Italian demographers have then have turned to family and family relationships to understand low fertility. They stress the crucial role played by the cultural system, but, provocatively, turn the second demographic transition theory on its head. This position is summarized in the "too much family" hypothesis by Livi Bacci, who, in somewhat playful terms, argues that it is just the excess of family ties that leads Italians to have so few children (Livi Bacci 2000, 2001).His argument in support of this claim is that intense interdependence between generations leads the younger generation to assume a perennial status of children, which in turn leads them to avoid, postpone, or at least limit, their assumption of parental responsibilities and commitments. Broadening the scope of the too much family hypothesis to include the institutional context, Dalla Zuanna (2001) proposes that the peculiarity of the Italian cultural system is that the centrality of family extends to all institutional levels. A familistic interpretation of low fertility posits that strong family ties would not only define relations and commitments in the private sphere among family members, but would also alter the functioning of the labor and housing markets in such a way that limiting family size to the minimum becomes the only rational choice to make.

Italy counts among those European countries that have a strong family system, which is defined by Reher (1998) as a system in which "traditionally the family group has had priority over the individual". Rough indicators that this system is operative are a high percentage of young adults living with their parents after age 25 (Del Boca 2002:12, Sgritta 2001; Palomba 2001), liv-

\footnotetext{
${ }^{1}$ This chapter is part of a larger research project (ELFI: Explaining Low Fertility in Italy) supported by grants from the National Institute of Child Health and Human Development (R01 HD048715) and the National Science Foundation (BCS 0418443) under the direction of David Kertzer, Michael White (Brown University USA), Laura Bernardi (Max Planck Institute for Demographic Research, Germany), and Marzio Barbagli (Istituto Cattaneo, Italy). For more information about the project, see: http://www.demogr.mpg.de/general/structure/division2/irg-cr/152.html. The authors would like to thank the editors and the several colleagues who gave useful comments on previous versions of this chapter, the project associates Vladimira Desogus, Francesca Melone, Rosa Parisi, and Alessandra Gribaldo who collected the interviews and managed the ethnographic data, and Chris Wright for language editing the manuscript.
} 
ing very close to their parents after marriage (Cioni 1997:215, Sabbadini, L. 1999), and keeping in touch with their parents by frequent visits or telephone calls (ISTAT 2006). Cohort studies show that, contrary to all theoretical predictions, intergenerational bounds are even more common in the younger cohorts than in the older ones (Barbagli et al. 2003:174).

The arguments that have been advanced in favor of the too much family hypothesis take the meaning and the practices of family relationships, and in particular relationships between parents and adult children, to be central for understanding fertility dynamics. They suggest that strong family ties inhibit or delay the formation of nuclear families. One argument is that in contexts where children are expected to co-reside with their parents for 30-35 years on average, couples may be discouraged to engage into parenthood in the first place, because this would mean having to provide for their offspring for a very long time. A second argument states that residing with one's parents for a prolonged period may weaken the desire to live independently, because the longer that young adults live with their parents, the more they become accustomed to a highconsumption lifestyle and the less they are inclined to settle for a lesser lifestyle in order to have children on their own (Del Boca 2002:12, Sgritta 2001; Palomba 2001). Family formation would appear as an increasingly challenging task as time goes by.

We argue that the strength of intergenerational relationships in Italy is, indeed, one important element in understanding low fertility in this country, but that the role that family plays in a couple's fertility decisions needs to be understood in light of the wider context of normative influences on life-course transitions. While choices about childbearing rest with the couple, the background against which such choices are made is provided by the set of actual relationships in which the couple is embedded before they form a union, at the time in which they get engaged, and after, despite the residential independence of the new nuclear family. International research on the influence of close ties with the extended family on the nuclear family has focused on the following: the effect of these ties on the definition of gender roles within the couple (Bott 1957); social support provided to the nuclear family (Bengston 2001, Wachter 1997); and social influence on fertility decisions due to sanctioning or imitation mechanisms (Bernardi 2003). However, none of this research explores the issue of how parental and filial relationships among non co-resident adults are constructed by daily practices and how they are experienced by the younger and the older generations involved. What is the meaning of strong intergenerational ties? How do they contribute to building other family relationships? What responsibilities do these relationships carry with them? In what ways do strong family relationships hinder or promote the creation of a 
new nuclear family? Unless we can provide answers to these questions, the too much family hypothesis remains fascinating but ungrounded .

In order to answer these questions, we investigate the case of family formation in contemporary Sardinia, where a strong emphasis on family solidarities parallels a very rapid fertility decline. More precisely, we focus on the processes that lead to the formation of new couples and on the influence of family configurations on such process. Normative and ideational influences directly affect family formation and, in the long run, indirectly affect couples' fertility decisions. Sardinian fertility trends could scarcely be more striking, given that fertility has fallen from Italy's highest to its lowest in less than half a century, . At the same time, in this region, strong horizontal ties among female siblings have, for a long time, been accompanied by a social organization based on the nuclear family and this still constitutes an important aspect of the local culture of reproduction today.

Given its dynamic socio-demographic developments, Sardinia provides an optimal case study for research on the relationship between strong family ties and fertility. Fertility in the inland, has dropped dramatically from generation to generation. The period total fertility rate (TFR) which was 2.92 in 1971, one of the highest in the country, dropped to the extremely low level of 1.04 in 2001 (ISTAT 2004). The decline in fertility occurred first as a result of a decline in higher order births, and recently also as a result of an increase in the number of women who either postpone motherhood or remain childless. Figure 1 compares the parity distribution of women born in 1920 and in 1963 in Sardinia to that of the rest of Italy, distinguishing the latter in three macro regions, North, Center, and South. The Sardinian pattern of the earlier cohorts resembles the pattern of the southern regions, while, for the younger cohorts, it shifts towards the typical northern pattern, characterized by a high percentage of women who have had no children or only one child. 
Figure 1- Parity distribution of women of cohorts 1920 and 1963 by macro regions and Sardinia . (Source: ISTAT 2004)
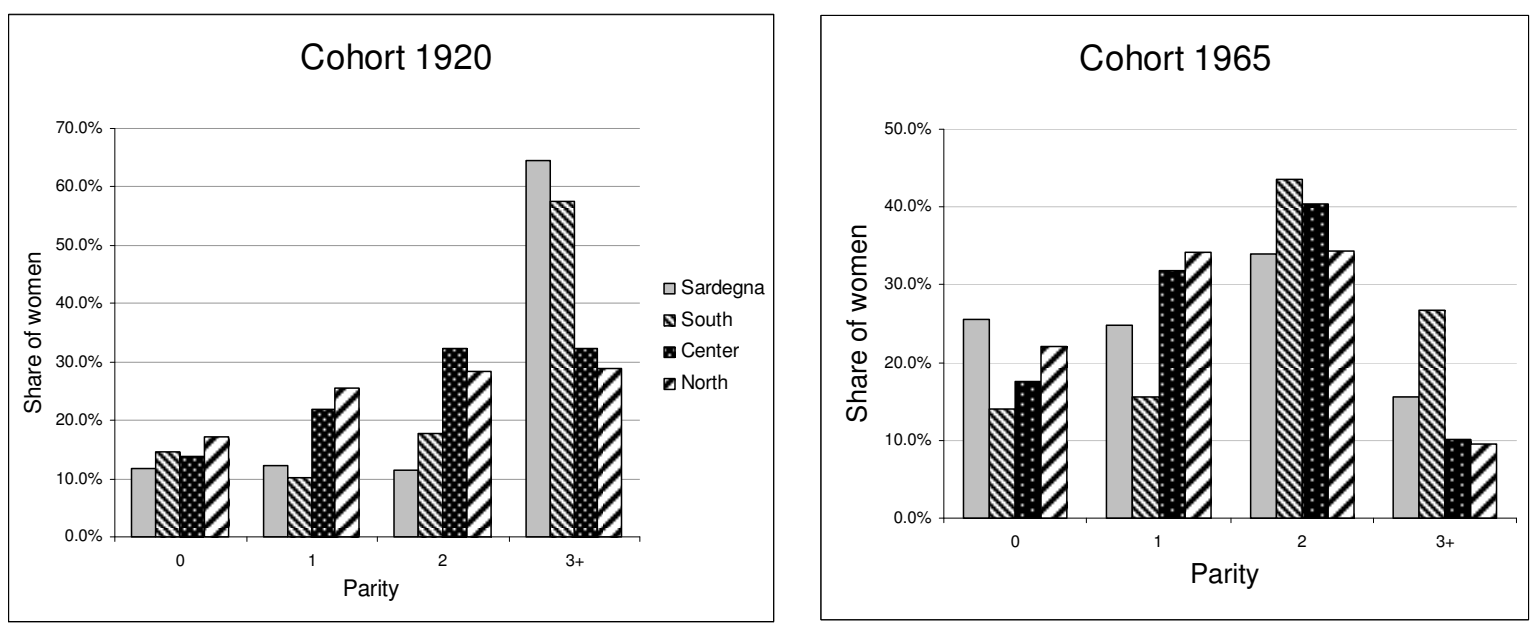

Like in the case of fertility, there are large regional differences in the age at motherhood and in celibacy prevalence. The mean age at first birth of Sardinian women in 2001 is estimated to be 29.3, one of the highest in Italy (ISTAT 2004), and definitively high if contrasted with the age of 27.2 of the southern region of Campania and the age of 27 of the other large Italian island, the region of Sicily). A significant feature of the Sardinian family history is the high proportion of women who never entered a union. For all cohorts born between 1941 and 1970 by age 30, the proportion of "singles" is always higher than $20 \%$ and reaches almost $40 \%$ in the younger generations; these figures are extremely high in comparison with those characterizing other regions. (Bernardi et al. 2007). Given the endogenous relation between union and fertility processes in Italy, where very few children are born outside a union, the composition of the population with respect to marital status may explain most of the difference in the parity distribution. The force opposing motherhood seems to work through the low prevalence of union formation. Indeed, regression analyses show that once union status is controlled for, the chances of having a first child turns out to be the same in Sardinia as in other regions (see Bernardi et al 2007).

The macro evidence presented so far points to the rapidity of family dynamics in Sardinia. Explanations for the rhythm of these changes, peculiarly rapid if compared with the other Italian regions, have been mainly focusing on the family history of the island. Sociologists and anthropologists argue that Sardinia differs from the other southern regions because of a peculiar social organization which strictly developed within an economy characterized, in large part, by pasturage 
(Oppo 1990). The social organization of the family and the gender models are shaped by the central role that women and their family of origin played for the newly formed couple ${ }^{2}$.

In Section 2, we argue that the centrality of maternal kin female networks have been a constant aspect of family configurations in Sardinia. Section 3 describes the set of original data that we used for our analyses. In the same Section we also introduce the concept of familyhood and discuss its relations with the exchange of care and support among close relatives, as well as the role it plays with respect to couples' fertility. In the concluding Section 5, we discuss the implications of familyhood for the too much family hypothesis. The contribution of this chapter must lie in its interpretation more than in the representativeness of the facts described, because the small sample is not representative of a definite population. Thus the value of the analyses of the Sardinian case lies in the attempt to develop hypotheses of general relevance that may subsequently be tested and compared with other case studies.

\section{A history of women-centered family configurations.}

The nuclear family and the neolocal residence after marriage have a long tradition in Sardinia. From the second half of the nineteenth century, spouses have aspired to have an independent housing, in both agricultural and shepherd populations. Conjugal nuclear families were embedded, as in most of the rest of Europe, in a net of cognatic kin, which accurately distinguished the group of siblings that belonged to the maternal side from those that belonged to the paternal side. While the two kinship lines were of comparable relevance during ceremonies, the maternal kin were predominantly present and preferred in daily interactions and exchanges. This preference has been explained by the fact that in conjugal families, the relationships among fathers, sons, and brothers within one family were often tense because of conflicts related to the hierarchical division of labor and allotment and inheritance of landed property. Such tensions contributed to the fact that often, younger sons did not maintain collaborative work relationships with their father and brothers once they left home. In contrast to men, consanguineous women were connected by a strong web of solidarities that were not modified after marriage and were concretely expressed in extended

\footnotetext{
${ }^{2}$ Pasturage, and the related long absence of men from the household, is at the base of the matriuxorial residence after marriage, typical of this region from the second half of the eighteenth century. However, this residential pattern was also common in agricultural communities in Sardinia. In general, household continuity was represented by women and their family, because mothers and their married daughters continued to live close by. The younger ones, who were not married, were often sent to serve in other houses. Some aspects of the more modern neolocal residential patterns are related to the old women-centered family. On the one hand, sons-in-law are much more involved and absorbed in their wife's family of origin than she is in his family. On the other hand, social support among sisters is very strong.
} 
work cooperation and an effective exchange of support across families (Bodemann 1988). Within each nuclear family, such collaboration extended to the in-laws after the marriage of one of the daughters. It was customary that a wife and her children retained a net inclination towards the maternal kin and that a future husband was absorbed by his future wife's kin just after the engagement (Solinas 1990, Anfossi 1968, Oppo 1982, Ornu' 1980). Kin solidarities were built along the maternal line and relationships among women. Universally accepted social norms prescribed that during a delivery, the woman's mother rather than the mother-in-law should be present to assist in the birth. Similarly, an old dependent parent should be taken care of by a daughter and not by a daughter-in-law. In daily and exceptional needs the maternal kinship, not paternal, should be activated. The most frequent family configuration of actualized relationships was constituted by the group of sisters, married and not, that was grouped around their mother. If the mother was alive, , a hierarchical rule based on age organized the sisterhood in a relation similar to a mother-daughter relationship. In large and articulated kinship groups, the sisters would be joined by close cousins, by aunts from the maternal side, and occasionally by grandmothers. The larger and denser the group, the more influential it was. The more influential the group was, the more influential every single woman that belonged to it.

The presence of these gender-specific family configurations that shaped kin solidarity networks meant that, despite their exclusion from the main productive activities (agriculture and cattle), women maintained a sovereign influence on the household and family businesses. Though they were formally subordinate to men in symbolic and material terms, Sardinian wives and mothers were autonomous and central figures in all decisions concerning the economy of the household-family. The influence of wives' and mothers' over their husbands and children ${ }^{3}$ grew along with their age and skills (Meloni 1984, Murru 1990). The inclination towards the maternal kin, of a female-centered web of solidarities, and the domestic leverage of the wife-mother, seem to originate from an ancient family type that prescribes the matriuxorilocal residence of the newly married couples. The spouse would move into his parents-in-law's household or, if this was too small or already occupied by her sisters' conjugal families, into an adjacent household. Census data for the eighteenth century and the first three decades of the nineteenth, census data show that

\footnotetext{
${ }^{3}$ The strongest influence was exerted on the daughters, who as children, helped the mother with the domestic tasks and were naturally socialized into the web of solidarities.
} 
those residential configurations were built around a widow who was the effective head of the household (Besta 1940) ${ }^{4}$.

The transition to the nuclear conjugal family did not proceed without costs, mainly demographically. From the second half of the nineteenth century, nuptiality rates, especially male nuptiality, in Sardinia have been lower than in Italy and much lower than in the Southern regions of the country (Somogyi 1967, Golini 1967, Rettaroli 1987) ${ }^{5}$. One hypothesis has been advanced to explain such pattern: the diffusion and affirmation of the neolocal residential pattern and the nuclear family that occurred in the same period, particularly in the pastoral regions. In this context, the spouses were expected to set up a decorous independent household out of their own resources, which needed to be accumulated before marrying. In Sardinia, young men usually worked in the fields or as shepherds for their fathers or for a master, while young women were sent to serve in other households if their own was too poor. Such circumstances made marriage an expensive step, with the consequence that not only did engagements usually lasted for many years, but they also often failed to culminate in a marriage. Age at marriage and the rate of celibacy in this system were relatively high. As a consequence, fertility was curtailed by restrictions imposed on the number of women entitled to marry and by the marriageable years. There is evidence that some parents, particularly mothers, resisted to the marriage of their last daughter (the last to live in the parents' household) so as not be deprived of domestic help, and when they became old, her assistance and care.

The high fertility of married couples, which was possibly a response to high infant mortality (one of the highest in Italy until the 1940s), was accompanied by a practice of late marriages and by high levels of celibacy. Women continued to be the center of the household and responsible for its economic and moral success. In this context, maternity was at the same time inevitable and needed to be harmonized with many other duties and responsibilities, as well as with the maintenance of household respectability. The gender division of tasks and sphere of influence were both clearly defined. Women were responsible for household production, its eco-

\footnotetext{
${ }^{4}$ These family configurations looked like a very dense neighborhood made up of sisters and their husbands, governed by their mother or their older sister when the mother died. These women continued to share the domestic chores, the children's education, and other forms of sociability. The borders between nuclear families were confounded by the intense exchanges. Occasionally, members of the families were exchanged. It was practice that when one sister could not have children, the most fertile sister would let her have one of her daughters, who was considered thereafter the recipient's child. This archaic residential model was in place until the first half of the nineteenth century in the area of the island that had not yet been reached by attempts on the part of the State and the Church to introduce consistent patrilineal principles (Oppo 1990).
} 
nomic management, children's education, and the dignity vis a'vis the community. The mer'e' duтu (female household head) had an authoritarian role, a role in which daughters were instructed starting from a very young age by their mothers, but especially by the larger network of female relatives (Meloni etc.) ${ }^{6}$.

This model of family formation lost most of its rationale with the crisis of the agricultural and pastoral economy. External influences, the growth of labor market incomes, and the increase in income levels left women and girls who had previously contributed to the household production without an occupation. Women's schooling and participation in the labor force grew more rapidly than that of men and more rapidly than in other southern regions ${ }^{7}$. Despite the proportion of women present in non-household production increased very rapidly from the 1970s so that 30 years later it is the highest in the southern part of the country, the rate of women's labor force participation is relatively low compared to that in the northern regions of Italy..

This development is consistent with the traditional model in which women contributed economically to the creation of the new household. With changes in the economic conditions, some changes in women's life course patterns occurred rapidly, such as the drop in fertility and the rise in women's labor force participation. Other aspects, such as a high age at motherhood and a rigid sequencing of life transitions, stayed relatively stable. Those changes which represent continuity with the past, or at least are not in contrast to it, can easily make their way. Those that entail discontinuity encounter a stronger resistance. An example of the first kind of change is women's enrollment in education and in paid jobs (continuity), as long as these activities precede family formation and can be regarded as the modern (market economy) version of the household work or going to work in another household. Essentially, this change does not endanger the old sequencing of events, in which domestic work or paid employment and family formation were followed rigidly and not in competition with each other. However, adverse structural contingencies related to the labor market and public service (generally, scarcity of jobs, uncertainty of employment, high contractual precariousness, little protection for motherhood, need for long distance

\footnotetext{
${ }^{5}$ With the exception of the years between 1890 and 1920 in which there was a relative economic improvement in living standards.

${ }^{6}$ This role seems to distinguish Sardinian women from their sisters in the richer north and center regions, where women became active in non-household production already at the beginning of the twentieth century, and in the similarly less developed regions in the south. Here, in the rest of the southern regions, and despite local variations, the role of women was confined within the borders allowed by the emphasis on man's control over them, a concept of honor, male honor, related to sexuality, and by the centrality of the relation between sexuality and maternity

${ }^{7}$ The reduction of fertility through the reduction of higher parity births its essential to social mobility under the new conditions.
} 
commuting, and little infrastructure to support young parents) demand a high investment in education, a long-lasting job search, and carry with them a fundamental difficulty in combining work and family.

These difficulties have important consequences in a context where the "double presence" model of combining family and work represents an example of discontinuity in the life-course with respect to the past patterns. The result is that women face a choice between two drastically different life patterns. One consists in postponing or forgoing union and parenthood until all other transitions are completed, risking running after constantly moving-forward targets in vain. The alternative pattern is to give up education or, more often nowadays, stability personal employment and, if the partner's income allows for it, focus on motherhood as the main source of realization. Yet, how are these choices made? How are orientations towards family and work developed and maintained in such a context? In order to answer these questions, we need to examine empirically how ideas about work and family are created and evaluated in this context (see section 4). However, strong female-centered networks are important also after the choice is made and a new nuclear family is formed. Maternal kin female networks offer a valid support to the double burden, by providing regular and emergency childcare or material supplies. Survey data give us only a rough indication of the frequency of contacts and the residential proximity among relatives and with parents and children at the moment of marriage. These indicators suggest that relationships with the close kin network are tight but they do not allow to distinguish whether it is maternal or paternal kin. In Figure 3 we display the number of close kin (parents and siblings) with whom women of different cohorts exchange visits more than once a week in Sardinia and in the northern region of Emilia Romagna ${ }^{8}$. The data refers to the moment in which the survey was carried out (and they were collected in 1998 and 2003) ${ }^{9}$. If we compare the younger groups of cohorts (from 1951 on) it appears that $30 \%$ to $40 \%$ of the women in Sardinia exchange visits with four or more close kin more than once a week, compared to 10 to $20 \%$ in Emilia Romagna. The higher number of close relatives visiting is certainly related to the larger number of close relatives available (parents are younger and siblings more numerous) and we cannot distinguish between available and unavailable kin with these data. However, even though we cannot establish whether the heavier presence of Sardinian relatives is the consequence of a higher preference for family contacts than

\footnotetext{
${ }^{8}$ Emilia Romagna is a region in the northern part of Italy. It has been chosen for comparison since its figures approximate the average figures for Italy in this domain.
} 
in the Emilia Romagna case, it is a fact that they are present and relatively more numerous. There is some evidence that the closeness of ties has consequences for the timing of couples' fertility.

Figure 3. Distribution of women by frequency of visit of close relatives more than once a week by region and cohort (Source: FSS 1998 and 2003)

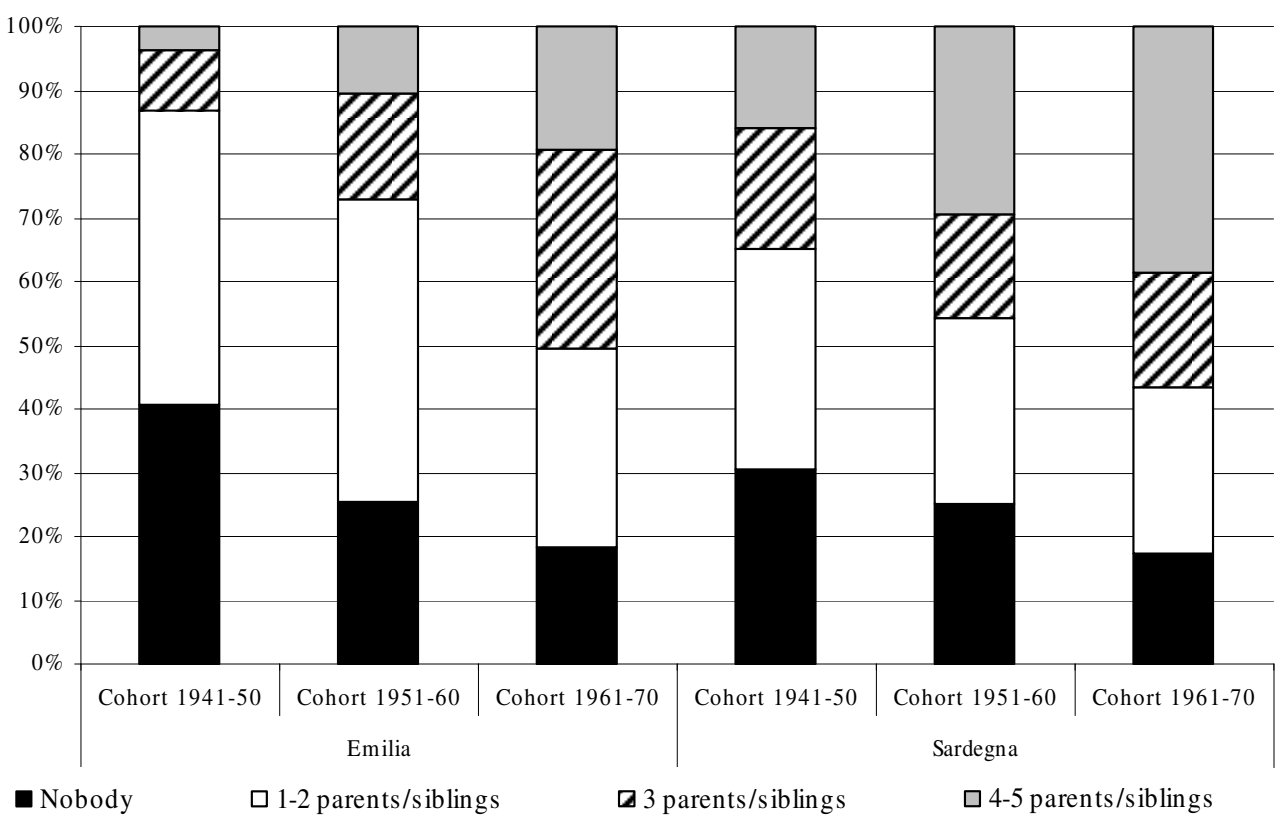

\section{Data}

The main corpus of empirical data that constitute the basis for this chapter consists of 74 semistructured interviews with women between ages 23-42 who were resident in Cagliari. In addition, we used the fieldnotes produced by several months of ethnographic observation of social practices related to intergenerational relations, gender relations, and parental roles. With a population of 155,000, Cagliari is both Sardinia's regional capital and its largest city. A substantial percentage of its residents are immigrants from inland areas (Oppo, 2004, 198-199). In most cases these are first- or second-generation migrants that have family networks that extend over a large area. The sample was purposely chosen via a complex snowball sampling stratified by age, parity, and mari-

\footnotetext{
${ }^{9}$ We use the ISTAT cross section surveys Famiglie e Soggetti Sociali 1998 and 2003. These multipurpose surveys have largely comparable information collected from large samples of about 50.000 individuals that representative at the regional level.
} 
tal status of the woman in order to maximize the variation in the major socio-demographic characteristics usually associated with fertility behavior (Table 1). In order to capture discourses and interpret meanings with respect to reproduction, we judge it important to have a relatively wide range of parities represented. As a result, the women range from childless to mothers of five. In 21 cases, we were also able to interview the woman's partner and, in 11 cases, the woman's mother. The interviews touched on union and fertility histories, the upbringing in the family of origin, the current relations with relatives and partner, and practices, intentions and expectations related to parenthood.

Table 1 about here - Sample, selected characteristics (Cagliari 2004-2005)

\begin{tabular}{l|cc|c|}
\cline { 2 - 4 } \multicolumn{1}{c|}{} & \multicolumn{3}{c|}{ Number of women-interviews } \\
\hline Age groups & $\mathbf{2 3 - 3 2}$ & $\mathbf{3 3 - 4 5}$ & all women \\
\hline total sample & 33 & $\mathbf{4 1}$ & $\mathbf{7 4}$ \\
Parity & & & \\
childless & 23 & 12 & 35 \\
one child & 4 & 13 & 17 \\
two children & 3 & 14 & 17 \\
three children & 2 & 1 & 3 \\
four or more children & 1 & 1 & 2 \\
Education & & & \\
low education & 5 & 10 & 15 \\
medium educaiton & 16 & 19 & 35 \\
high education & 12 & 12 & 24 \\
Civil status & & & \\
married religious & 8 & 25 & 33 \\
married civil & 0 & 1 & 1 \\
cohabiting & 5 & 4 & 9 \\
single & 5 & 5 & 10 \\
engaged & 15 & 4 & 19 \\
divorced & 0 & 2 & 2 \\
\hline
\end{tabular}

With these data, we examined desires, expectations, and behavior related to family formation and relations that reflect the underlying culture of reproduction in Cagliari. Independent of the particular behavior of the individuals who give voice to them, basic beliefs, values, expectations, and perceptions constitute the context in which reproduction acquires meaning. They express the norms internalized during early socialization, as well as the more implicit and dynamic enculturation process that is produced daily through practices and family relations. In this chapter, we apply content analysis to the interview texts, paying particular attention to the interrelations between non co-residents, close kin members (mostly parents, children, and siblings) and how the reciprocal responsibilities enter the discourse of family formation and enlargement. We focus on ex- 
pected and performed care and how they are related to the definition of family, of intergenerational responsibilities, and ultimately to fertility decisions

\section{Women Family Configurations, Care, and Fertility}

The exchange of care and support, and more general reciprocal collaboration among family members, are taken-for-granted unless specific circumstances, such as incompatible time schedules, geographical distance, physical handicaps, or a rupture in normal family relations, make institutional and professional care necessary. Family care and support provided among a range of relations, from grandchildren to elderly parents, and in a range of situations, from daily routines to occasional emergencies. Explorative analyses on regionally representative data for Italy suggest that, once individual characteristics and regional residence are controlled for, living close to parents at the moment of marriage, is positively correlated with first and second births, while a higher number of close kin visiting more than once a week is correlated negatively and significantly with the same events. In other words, family relationships would have an effect on the timing of births, though whether such effect is positive or negative depends on the indicators used (Bernardi et al 2007).

Taking advantage of the ethnographic and interview data described in the previous section, we analyse the set of expectations and practices associated with the exchange of care among family members. When a child is born, also family relationships are thereby created: grandparental, siblings and agnatic relationships. Becoming parents involves creating potential family relationships beyond the direct relation of the parents with the new-born; hence these relationships, the meaning attributed to them, and the exchanges they entail are likely to influence fertility decisions. In particular, we examine vertical exchanges of care services (parents and grand parents to young children, adult children to ageing parents and grandparents) and the implications they could have for fertility. By using data from the personal interviews we hope to disentangle the meaning and functions attached to relationships with close relatives beyond the nuclear family (parents and siblings). We focus on expected and performed care and how such care is related to the definition of family, of intergenerational responsibilities, and ultimately to fertility decisions.

We concentrate here on the way in which considerations related to care and support are explicitly related to fertility decisions in the narrations. In Sardinia, these services are mostly provided by, and expected from, women; a web of daughters, sisters, mothers, and grandmothers. Therefore we will talk mostly about women. However occasionally, and especially in relation to 
support, men will enter the picture (Oppo 1991). Two relational domains that stretch beyond the single nuclear family horizontally and diagonally appear in the narratives to be particularly relevant for our interest in the construction of familyhood beyond the nuclear family relationships: the relations among adult siblings and those between future parents and sons/daughters in-laws.

\subsection{Adult siblings}

While fertility is very low and family sizes have shrunk considerably, horizontal relations among siblings and the practice of reciprocal support have retained the full force of their importance. When these relationships are absent, either because the respondent is an only child or because there have been family conflicts, they are regretted. Contacts with siblings in adult age are reported to be frequent in practise and valued in meaning in the interviews. By contrast, men and women in Cagliari evaluate to the lack of kin relations, horizontal and vertical relations, negatively. For example, the idea of a only child is associated with negative attributes like sadness, being spoiled, present and future loneliness, and having a burden to carry when the parents are old.

When the respondents mention sadness and being spoiled, they have in mind a child who does not grow up with brothers and sisters to share experiences with. Having sport or school friends with whom to socialize is a poor substitute for the complex of educational and supporting relations that develops within the family. This 31-year-old, highly educated, childless woman remembers the relationships in her family.

\footnotetext{
"Clearly it (having siblings) helps supporting each other when you are a child and your mother does not understand one or the other... my sister helped me several times, she went and mediated with my mother, or I was doing it, these are the good aspects, sharing every single moment of the day, I mean moments like lunch, in which you are not alone, but rather with an age mate, I find it nicer (woman under 30 and childless)"
}

The second two aspects of being an only child, loneliness and having a burden to carry, are mostly related to the child's future as an adult, when he will be responsible for caring for his ageing parents in solitude.

"it is important for when you are adult, maybe because I have a good relationship with my siblings and I know that, should I have any trouble, they are there (...)basically, for when you are adult because, also for thinking about your parents, when they get older, thinking about these things, having the support of another sibling... it is not like managing an ageing parent all alone...(...) I think it is not fair to leave it (a child) alone" (woman over 40, mother of 2 children)

"he (a only child) feels alone in the sharing of family problems. For instance this friend of mine was saying: 'should I imagine that one day my parents will not be there anymore, I would get very sad, 
even more because I would know I am alone". She thinks "ok, there are cousins, but it is not the same". ... so for instance, with a sick parent at the hospital, having a brother or a sister helps, also with managing the timing, the organization, the caring for the parent" (woman under 30 and childless)

Siblings are relationships that parents donate to their children, a reciprocal support which is expected to be there for the rest of their life.

It is good that one can count on someone, having always a support, but also just a way out, I don't know, for anything, a problem, just anything, I think a brother or a sister will never abandon you, that's it (woman over 30 and mother of two children)

Survey data support such impressions: the already mentioned Family and Social Subject Survey 2003 asked the respondents to which of the non co-residing members of their social network, they had given the most important help in the four weeks that preceded the survey. In Sardinia, siblings and their children were the second most important receivers; $17.8 \%$ of respondents indicated that they had helped them ${ }^{10}$.This value is second only to another region and far higher than the national average (12.3\%). The recurrent concern of having siblings help to care for old parents and the wish to experience a sense of family unity are often given as a rationale for having at least two or three children, rather than just one. Those who argue in favor of having only one child do invariably so by citing examples of poor relationships among siblings that they have experienced directly or vicariously. In our sample, frequent examples of "help" are to be found among sisters who provide childcare for their nephews and nieces. However, more than childcare, strong and frequent relations of aunts and nephews/nieces, recurrently reported by the respondents, is experienced as a normal relation that one would wish to have with one's family members. There is nothing exceptional in spending a great deal of time with one's sister's children as the 35-year-old childless woman points out in this extract from her interview:

A: Have you ever taken care of a child?

I: Yes, I have nephews, I have a lot of them. I take care of them when that they come and visit me at home, or when I spend time in their company, or when I help them with homework, I play with them, if necessary bringing them to the beach, when they are young. I enjoy bringing them fishing, but of course, they are not my children, of course.

A: They are your siblings' children?

I: Yes

A: How many other brothers and sisters do you have apart from the sister who is living with you?

I: We are five all together. There are two more sisters and one brother, all married.

10 Siblings and their children come after friends (28.2\%). Friends are the most important receivers in every region. We must remember that often siblings do co-reside for a long time in parents' homes and therefore are not eligible to be mentioned in this category. It is likely that the percentage of help given to co-residing siblings is even higher. 
A: And they have all 3 children?

I: Yes, yes, yes.

A: The three of them. And how did you like this experience of taking care of children?

I: Normally, it is a normal thing, I mean it is part of the family, we are all part of the family, therefore it is normal" (woman over 30 and childless)

Often, sisters who do not co-reside, visit each other a umber of times a week ("we talk to each other very often, I go very often to her place, when possible, when I have free time always, I feel like at home") in some cases to the point of substituting relationships with siblings for those friends ("my sisters are my friends" as one respondent put it when asked to describe her friendship network). Generally, though, strong relations among siblings ideally contribute to the creation of the family as a unit over time, as this 33-year-old mother of two, explains:

I: They increase the (sense of) union.

A: Union between whom? Between the two parents?

I: No, the union between children and parents. (Among) siblings? (...)

A: So having more children....

I: Yes, yes, yes, it (the family) is more complete in my opinion.

(woman over 30 mother of two children)

Care and reciprocal support are loaded with meaning that go beyond their mere functional role. They are a means by which the sense of family itself is constructed, in that they are a daily channel for transmitting affection, discipline, habits, and knowledge to the children. When the respondents say that at least one child is necessary to "to create a family", they express more or less consciously two aspects of family making. On the one hand children are the fulfillment of individuals, couples, and the larger family group because without them there would be no uncle, aunt or grandparent figures. On the other hand, and more importantly for our argument, they express the intense meaning of caring as a time for family creation. The term famiglianza (familyhood) expresses the sense of identity provided by being part of a social group of relatives. Far from being an abstract construction, familyhood depicts the concrete consequences of the interdependence created by family practices, beginning with caring and shared daily activities. The term famiglianza indicates "the feeling of common belonging which derives from the relationships internal to the family"; it brings together concepts such as the willingness of the individual to make sacrifices for the good of the group, the affective feeling of being attached to the family, and the reciprocal exchange of help. (Colombis 1997: 402) ${ }^{11}$. Attachment and reciprocity, in particular,

\footnotetext{
${ }^{11}$ Colombis created the term as a reaction to the thesis of the amoral familism with which Banfield highlighted the opposition family and civil society. This opposition had a negative connotation, because the strong sense of belonging
} 
seem to define familyhood in contemporary Sardenia, which ideally binds together grandparents, children and siblings. In practice, the family configurations that concretely express familyhood are the vertical and horizontal bonds with the maternal kin.

\subsection{Long engagements and the slow construction of in-law relationships}

Familyhood is constructed in the family of origin and involves the future conjugal couple even before the formation of the nuclear family; namely, during the period of engagement. Very long engagements (sometimes more than ten years) are a common experience for the young adults we interviewed in Cagliari.

In our sample, 19 out of 74 women declared themselves to be engaged without co-residing with their partner and many more have been engaged before marrying, entering a union, or returning to solitary status. An engagement usually involves both partners' family of origin. It is the time when "things get serious", as the respondents say, not only because partners grow closer to each other, but also because they are introduced to and embedded within each other's family networks. The respondents' narrations present engagements as the period in which the couple's projects (living together, becoming parents) develop. The conditions that are necessary for having children are articulated without too much reflection. Women seek to complete their education and, for those interested in a career, establish themselves in their profession, or at least obtain some financial stability, and possibly have well-furnished, sufficiently comfortable, independent housing in order to marry. Childbearing outside of marriage is hardly acceptable. Marrying without having met the conditions for independent living (possibly a house of property) is also very rare. Beliefs about the conditions under which it is appropriate to establish an independent household are shared universally. It is held that any deviation from this path would endanger the social respectability of children, as much as of their parents. These messages of respectability are transmitted from one generation to the other during the long periods of engagement, in which the future conjugal couple lives separately (each partner at his or her parents' home) while at the same time being gradually inserted into the parental network, often with daily interactions. The strong ties (consisting of a mixture of affection and responsibilities) that relate parents and children are learnt in this period of engagement, in which the partners are already viewed as belonging to the reciprocal family (particularly to her family) and treated as, and often called, in-laws. There are also 
evident advantages in involving families in an engagement: partners are allowed to spend more time together because they can frequent each other's houses, or they may receive financial help when buying a house, among other things.

Since familyhood is already under construction during the engagement, marriage and parenthood are just the last steps of a process that began long before and can therefore be deferred without creating major preoccupations. In fact, during the long engagement period, the parents provide emotional and material support as the couple faces the challenge of establishing financial and material security. The story of Lucia (fictive name) is telling: she is 27 , has just completed her university studies, and lives at her parents' home. She has been engaged to her boyfriend for several years. Her boyfriend lives at his parents' home. They regularly visit their future parents-inlaws' homes for lunch or dinners (even alone), they call them on the telephone, or they stay overnight (only at the boyfriend's parents' home is this allowed). Their parents got to know each other through their children and are on reciprocally friendly terms. When asked what the positive aspects of continuing to stay with her parents were, even though she is engaged and not studying anymore, Lucia said that:

"the fact that you go back to family is like a nutshell, a protection, a reference point, for an advice, for a conversation, for anything....(...) I am not waiting to leave home, I will have the possibility of choosing, maybe also to have a calm job before leaving, before making the step... (...)"(Cb02_0310dg0).

This sense of sequencing of life events is very evident in the analysis of some of the contradictory behavior related to the postponement of parenthood. When asked about her intentions to have children, a young married woman in her thirties said that she did not want to become pregnant at that time because she had not yet realized her plans with regard to her job and she perceived having a child as an obstacle to such plans. On the other hand, when asked whether she was using any contraceptive, she said that she had actually interrupted her use of the pill a few months before because she and her husband believed that they could take care of a child. This woman seems not to be able to formulate her intention to become pregnant in a positive way, yet has acted in a way that would enable her to become pregnant. Under such circumstances, should she have a child, it would not be the result of a conscious choice; it will simply have arrived.

There seems to be a parallel between the long-term planning of unions and the sense of order and discipline in the organization of daily life that was evident in many interviews and that emerged from field observations. The cohort of our respondents' mothers grew up with several siblings and themselves had, on average, three or four children. This meant that organization, 
planning, and educational rules (in short, family discipline) were crucial, independently of whether the woman was employed or not. The myth of the efficiency of some women is well expressed by the memory of one respondent: "Nothing could be left to chance". ${ }^{12}$ Discipline, rules, and tidiness were and are highly valued and mostly women's responsibility. Women, who spent most of their time at home in the past, were the providers of a 'private education' on the virtues of organization and planning for all members of the household. The most vivid and recurrent image of what their mother was like and how they see themselves as mothers, is that of the "mother both strict and sweet". These are essential qualities for making everyone "keep to the straight path" and at the same time creating a sense of relatedness and familyhood by following the same clear-cut rules. The daughters of these women, who are, on average, more active in the labor market, are still proud when they can claim to have inherited such virtues from their mothers. Their partners appreciate them and praise them for these presumed qualities, and those who feel they do not measure up voice their regret and are more uncertain of their role.

\subsection{The Legacy of Women-Centred Family Configurations}

Considerations of work and family are developed in accordance with expectations and responsibilities related to care and family. The choice of either (i) postponing union and parenthood or (ii) giving up education or employment to focus on motherhood is related not only to the economic and education status of the young woman, but also, and most importantly, to the family configuration in which she is embedded.

In order to highlight the effects of family configurations, we start with those configurations in which the nuclear families are not surrounded by a maternal female kin net. We observe that young women who are isolated from maternal kin are more likely to eschew the double presence model to welcome the first serious marriage prospect,, thereby (i) abandoning their educational pattern too early to have reasonable expectations of employment and (ii) devoting themselves to family and children. The isolation of a nuclear family may also hinder family formation for young women who have sole responsibility for ageing and dependent parents, particularly when affective ties are strong. When the social environment with respect to specific life course and family circumstances is mostly constituted by the husband's kin, married women are likely to have more

\footnotetext{
${ }^{12}$ This need for organized routines is strong in the childhood memories of a respondent whose mother was a teacher and mother of four. She recalls the smell of frying onions at 6 in the morning invading the house before breakfast because the mother was preparing the meal for all. Non-employed mothers would probably have spent a substantial part
} 
children than those who maintain closer contacts with their own kin. In these cases, a woman is very often encouraged to devote herself to family and children.

In contrast with these situations are those in which a woman is surrounded by a visible presence of maternal female kin members (her own sisters, her mother's sisters, her mother's aunties, a grandmother). This family configuration constitutes a strong platform of material and moral support to continue with education and pursue a satisfying profession. As in other cultures (see the chapter by Milardo in this volume), the aunt in particular, especially if she is not married, is a central figure during the adolescence and young adulthood of many Sardinian women. She often joins, or substitutes for, the girl's mother in taking care of the children, she mediates possible conflicts between mother and daughter, she occasionally supports the costs of studying, and she activates her network to help the girl to find employment. These services are particularly intense towards a niece, often her god-daughter, rather than towards a nephew or god-son.

Why are maternal kin female networks likely to discourage early family formation and fertility? The interviews provide rich data on the content of the exchanges between women on these topics. In the narratives, women report the repeated pregnancies, the physical pain, the daily fatigue, the poverty, and the lack of opportunities experienced not only by their grandmothers and great-grandmothers, but also, and more significantly, often times by their own mothers. Children are still universally appreciated. However, the main message from the female side of families is that the life of women should involve fatigue and sacrifice, but should also contain gratification that stems from activities independent from maternity. Many women who had lived their own lives totally absorbed by their household tasks now teach the younger female generation to finish school and pursue other objectives besides marriage and motherhood. The latter are not excluded, but are to play a secondary role.

\section{Discussion}

We have argued that strong family relations are gendered in Sardinia and that what is relevant for fertility decisions is the extent to which a young woman's family configuration includes a substantial proportion of female maternal kin. We showed at least two ways in which such gendered strong ties are relevant. First, strong ties among kin-related women still represent the principal resources for material and psychological support in daily and occasional circumstances. Our

of their days on meal preparation. This is another expression of how the time spent to care for family members, through food, creates an intense sense of familyhood 
interviews show that due to the extensive exchange of support, the expectations and opinions of female maternal kin in relation to fertility and family decisions hold great weight. Second, these strong ties among female maternal kin are the major vehicles for the socialization of young women and therefore have a great influence on their attitudes towards family and work. The generations of women we analyzed have been raised with a double emphasis on: (i) the importance of women's discipline and responsibility, and (ii) education and productive activity in the labour market. This double-presence model is conveyed as an aspiration, rather than as experience, from mothers and aunts to daughters and nieces. We noted the extent to which a double-presence model is very demanding in this context. On the one hand, education viewed as a status symbol, difficult employment conditions, and the necessity to contribute to the family income are experienced in a context that may suffer more from structural deficiencies than other regions. On the other hand, there is an image of family and familyhood that needs to be constructed and whose building blocks are togetherness, presence, dedication, and care that need to be distributed among a rather large number of ties. The construction and maintenance of this image is very demanding in terms of time and personal investment.

The formation of a nuclear family is preceded and followed by relationships of the future partners with their family of origin. Family relationships remain highly patterned and structured around caring practices, such as those between parents and their non-resident children, among adult siblings, among grandparents and grandchildren. Changes of residence often do not interrupt existing cross-family interdependencies, because people's commitments to each other continue thereafter. However, in Sardinia, these patterns are rooted in the history of family relationships; there, caring and commitment characterize maternal kin relations in particular, just as was the case in the past. While the content of the commitment and the exchanges may have varied with the societal and economic changes that took place over time, the relationships involved follow stable patterns. Family configurations remain centered around maternal kin members, who continue to constitute the set of interdependent individuals who share feelings of family belonging, and who experience a sense of connectedness or familyhood.

Inter-generational responsibilities shape the formation of couples' fertility preferences. The direction of such influence is twofold. On the one hand, fertility choices are affected negatively by close kin, partly because of the strong identification between old and new nuclear families that is established through relationships of reciprocal care. First, there is the emphasis placed by women of the older generation on subordinating marriage and motherhood to education and employment 
goals, and on limiting the number of children in order to be able to follow a double-presence role. Second, the potential and actual involvement of grandparents in their grandchildren's care gives grandparents an important role to play in couple's decisions about the mode and timing of their family formation. Third, the frequent contacts of adult children with parents and the early engagements represent a constant reminder to the young couple of the appropriate family formation patterns.

On the other hand, family support counteracts, to a certain extent, both (i) the negative effects of the economic and professional instability of the younger generation, and (ii) the deficiencies in state welfare with respect to care for children and the elderly. Young couples in their late twenties and their thirties face hardships in planning their family life, due to the particularly difficult labour market prospects in the island, where unemployment is relatively high. The strong emphasis on ordered life courses, tidy housing, and financial independence of each nuclear family defines an appropriate path for family formation and a reason for postponing marriage, more than hindering commitments. We are very far from a generation of 'Peter Pans,' childlike adults who are spoiled by their parents and live in their parents' home. Often, young couples are engaged and committed to each other right after school (if not before) and continue to be so for as long as a decade, working and saving for their future life as a married couple, sustained and supported by their families. These different influences show that fertility choices are affected by the family configurations in which couples are embedded. Expectations, obligations, and norms about work, financial independence, housing, childbearing, and childrearing that circulate within these family configurations define the framework for couples' fertility choices. If one were to focus on the members of the nuclear family without considering their larger family context, one would fail to appreciate the contribution of social influence to their decisions. In this sense, the stronger and closer the exchanges are, the stronger is the effect on couple's fertility decisions.

However, it does not seem that much family is too much works only in the sense of discouraging parenthood. Describing the strength of family ties as having an exclusively negative effect on young adults' fertility overlooks the extent to which family members' interdependence is perceived as a basis upon which to plan for independent living and as a stable source of resources to support these plans. Strong family ties may pull in opposing directions with respect to childbearing, such as discouraging the transition to parenthood yet providing support for parity progressions after the first child, as in the case of Sardinia. Simplistic theoretical statements that advance a univocal causal relation between strong intergenerational support and low fertility should 
be substituted by studies that are more informed of active family configurations and the way in which they become actualized through support and care at different moments of the life course.

One is tempted to ask whether there would be even fewer children born if this intergenerational dependency were not ensured by strong family ties, but such a subjunctive conditional is not testable empirically because it is not possible to set up a controlled situation for the antecedent. A better question is to ask what the current low fertility means for the development of family-based care and the construction of familyhood in the near future in Sardinia. Projections based on current trends suggest that family networks in Italy will be greatly reduced by 2050 , particularly in regions with the lowest fertility levels, such as Sardinia (Tomassini and Wolf 2000). A shrinking of the close nuclear family kin networks may generate a need to develop alternative ways of satisfying the demand for child and adult care. These alternatives may include a more extensive publicly funded social support (as, for example, in France and Sweden) or the involvement of networks of neighbors, friends, and charitable associations in family-like interactions (Wenger et al. 2000). Currently, the relationships beyond the nuclear family strongly affect its development in Sardinia, by both postponing the moment of its formation yet supporting it strongly. The necessity of introducing alternative care services will introduce a further discontinuity in this complex system of family formation, just as did the necessity for women to divide themselves between family care and a double presence. What consequences such development will have for fertility is an open issue.

\section{References}

Anfossi, A. 1968. Socialità e organizzazione in Sardegna, Milano, Angeli.

Barbagli, M., M. Castiglioni, and G. Dalla Zuanna. 2003. Fare famiglia in Italia. Bologna: Il Mulino.

Bernardi L. 2003. "Channels of Social Influence” Population Research and Policy Review.

Besta, E. 1940, "L'attribuzione del cognome nella Sardegna medievale" in Studi in onore di C. Calise, Milano, Giuffré, vol.1, 479-484.

Bodemann Y.M., 1988. Telemuda: Aspects of the Micro-organization of Backwardness in Central Sardinia, Ph. D. Dissertation, Brandeis University, Umi Dissertation Information Service, 189-195.

Cioni, E. 1997. "Il sistema di parentela" in Barbagli, M. and C. Saraceno (eds.), Lo stato delle famiglie in Italia.

Colombis A. 1997. "Invece del familismo: la famiglianza" In Meloni B. ed, Famiglia meridionale senza familismo. Strategie economiche, reti di relazione e parentela, Meridiana Libri, Catanzaro.

Dalla Zuanna, G. 2001. "The banquet of Aeolus. A Familistic Interpretation of Italy's Lowest Low Fertility", Demographic Research, 4(5), 1-29. 
Da Re G. 1990. Tutti uguali, tutti diversi. Formazione del gruppo domestico e modalità di trasmissione dei beni in G. Da Re, La casa e i campi, Cagliari, Cuec, 149-50

Del Boca, D. 2002. "The effect of child care and part time opportunities on participation and fertility decisions in Italy." Population Economics, 15:549-573.

Golini A. 1967. Aspetti demografici della Sardegna, Quaderni del Seminario di Scienze politiche dell'Università di Cagliari, Milano, Giuffre'.

ISTAT 2006. "Parentela e reti di solidarietà". Informazioni 26, Istat, Roma.

ISTAT 1997. "La fecondità nelle regioni italiane. Analisi per coorti”. Informazioni. 35, Istat, Roma.

ISTAT 2006. "Natalità e fecondità della popolazione residente: caratteristiche e tendenze recenti. Anno 2004". Nota informative, Istat, Roma

Kertzer, D. M White, L. Bernardi, and G Gabrielli 2006. "Toward a Better Theory of Very Low Fertility: Lessons from Italy”, MPIDR Working Paper 006-049

Livi Bacci, M. S. S. 2000. "Trop de famille et trop peu d'enfants : la fécondité en Italie depuis 1960", Cahiers québécois de démographie, 29 (2):231-254.

Livi Bacci, Massimo 2001. "Too few children and too much family”. Daedalus, 130(3): 139155.

Meloni B., 1984. Famiglie di pastori, Torino, Rosemberg \& Sellier.

Murru Corriga G. 1990. "La mathargia de oro", Ichnusa, (1):21-28

Murru Corriga G. 1993 , "Di madre in figlia, di padre in figlio. Un caso di 'discendenza parallela' in Sardegna", La ricerca folklorica, No. 27.

Oppo, A. 1991, "Madri, figlie, e sorelle: solidarieta' parenteli in Sardegna“, Polis, V (1): 2148

Oppo A. 1990. “'Dove non c'e' la donna non c'e' casa': Lineamenti della famiglia agropastorale in Sardegna", Journal of Family History 15 (4)

Oppo A., 1982. Il lavoro domestico nella società sarda tradizionale, in F. Manconi (ed.) Il lavoro dei sardi, Sassari, Gallizzi: 46-54

Oppo A, 2004 “Trasformazioni dei comportamenti familiari a Cagliari” in G.G.Ortu, Cagliari fra passato e presente, Cagliari, CUEC, 197-216

Orrù, L., 1980. Donna, casa e salute nella Sardegna tradizionale, Quaderni sardi di storia, 1 (1): $167-178$

Palomba, R. 2001. "Postponement in family formation in Italy, within the Southern European context," Paper presented to the IUSSP Seminar on "International Perspectives on Low Fertility, Tokyo, March 21-23.

Pinna, L. 1971 La famiglia esclusiva, Bari, Laterza

Reher, D. S. 1998. "Family ties in Western Europe: Persistent contrasts." Population and Development Review 24:203-234.

Rettaroli R. (1987) Età al matrimonio e celibato nell'Italia del XIX secolo: un'analisi regionale, paper presented at the Italian Historical Demography Association Meeting, Barcelona.

Sabbadini, L. 1999. "La permanenza dei giovani nella famiglia di origine. Modelli di formazione e organizzazione della famiglia." Paper presented at the Conference "Le famiglie interrogano le politiche sociali," Bologna, March.

Saraceno C. 2000. "Italian families under economic stress: the impact of social policies." Labour, 14:161-184.

Sgritta, G. 2001. "Family and welfare systems in the transition to adulthood: an emblematic case study". Seminar on Family Forms and the Young Generation in Europe. The European Observatory on the Social Situation. 
Solinas P.G., 1990. "Famiglia sarda e famiglia toscana: variabili mediterranee del tempo genealogico", in Oppo A. (ed.) Famiglia e matrimonio nella società sarda tradizionale, Cagliari, La Tarantola, :121-147.

Somogyi S. 1967. Sviluppo della popolazione italiana dal 1861 al 1961, «Annali di statistica», Roma, 1965, XVII, serie VIII, :236- 397.

Tomassini C. and D. Wolf 2001. "Shrinking Kin Network in Italy due to Sustained Low Fertility", European Journal of Population, 16: 353-372.

Wachter K 1997. "Kinship resources for the elderly", Philosophical Transactions of the Royal Society.

Wenger, C. A. Scott, and N Patterson 2000. "How important is parenthood? Childlessness and support in old age in England", Ageing and Society, 20: 161-182. 